\title{
Evaluation of the Residual Antigenicity of Dairy Whey Hydrolysates Obtained by Combination of Enzymatic Hydrolysis and High-Pressure Treatment
}

\author{
ELENA PEÑAS, ${ }^{1,2 *}$ PATRIZIA RESTANI, ${ }^{3}$ CINZIA BALLABIO, ${ }^{3}$ GUADALUPE PRÉSTAMO,${ }^{1}$ ALESSANDRO FIOCCHI, ${ }^{4}$ \\ AND ROSARIO GOMEZ ${ }^{2}$
}

\begin{abstract}
${ }^{1}$ Department of Science and Technology of Plant Food and ${ }^{2}$ Department of Science and Technology of Dairy Products, Instituto del Frío, c/José Antonio Nováis 10, 28040-Madrid, España; ${ }^{3}$ Department of Pharmacological Sciences, University of Milan, via Balzaretti 9, 20133 Milan, Italy; and ${ }^{4}$ Department of Child and Maternal Medicine, The Macedonio Melloni Hospital, via Macedonio Melloni, 20129 Milan, Italy
\end{abstract}

MS 05-541: Received 31 October 2005/Accepted 22 February 2006

\begin{abstract}
Dairy whey was hydrolyzed for 15 min with five food-grade enzymes (Alcalase, Neutrase, Corolase 7089, Corolase PN$\mathrm{L}$, and Papain) at atmospheric pressure (0.1 MPa) and in combination with high pressure (HP) at 100, 200, and 300 MPa, applied prior to or during enzymatic digestion. The peptide profile of the hydrolysates obtained was analyzed by sodium dodecyl sulfate-polyacrylamide gel electrophoresis (SDS-PAGE), and their residual antigenicity was assessed by immunoblotting with anti- $\beta$-lactoglobulin monoclonal antibodies and the sera from pediatric patients allergic to cow's milk proteins. Moreover, to evaluate the presence of residual trace amounts of casein in bovine whey hydrolysates, immunoblotting with anti-cow's milk protein polyclonal antibodies was performed. SDS-PAGE analysis showed that HP treatment increased hydrolysis by the proteases assayed, especially when it was applied during the enzymatic digestion. Positive reactions at the band corresponding to $\beta$-lactoglobulin were detected for Corolase PN-L and Corolase 7089 hydrolysates, except for those obtained under $300 \mathrm{MPa}$ by the last protease. However, the immunochemical reaction was lower in the hydrolysis products obtained under HP than in those obtained at atmospheric pressure and after the HP treatment. On the contrary, no residual immunochemical reactivity associated with $\beta$-lactoglobulin was observed in the hydrolysates obtained by Alcalase and Neutrase under HP, and none was observed in any of the hydrolysis products obtained by Papain. The presence of traces of casein was not significant. These results suggest that HP combined with selected food-grade proteases is a treatment that can remove the antigenicity of whey protein hydrolysates for their use as ingredients of hypoallergenic infant formulae.
\end{abstract}

Breast feeding is the most suitable form of nutrition for neonates because of the specific nutrients as well as the growth and defense factors contained in human milk (16). When breast feeding is not possible, children are generally fed cow's milk formulae, which can induce immunological responses in some allergic subjects. This syndrome is known as cow's milk allergy, and its prevalence ranges from 0.5 to $7.5 \%$ in infants who are fed formulae containing cow's milk proteins (10). For this reason, hypoallergenic formulae based on protein hydrolysates have been developed, to reduce the antigenicity of milk proteins. However, several reports have described residual immunoreactivity, even in these preparations $(5,21,24-26,30)$.

Over the last decade, high pressure (HP) has been described as an excellent nonthermal technique for food preservation (19), because the microbial population can be decreased without modification of the sensorial and nutritional properties $(22,23)$. HP is a valuable tool also in the production of hypoallergenic protein hydrolysates, as shown by several scientific articles in which the enhancement of enzymatic proteolysis of bovine $\beta$-lactoglobulin by different proteases in combination with HP has been described

* Author for correspondence. Tel: (+34) 9154923 00; Fax: (+34) 91 54936 27; E-mail: elenape@if.csic.es.
$(3,6,7,13,18,31)$. A selective hydrolysis by thermolysin in whey protein concentrates under $200 \mathrm{MPa}$ was found by Hayashi et al. (9), and an increase of the proteolytic digestion of soybean whey proteins by pepsin, trypsin, and chymotrypsin combined with HP, applied prior to or during the hydrolysis, was shown previously by our group (19).

Nakamura et al. (14) described a reduction of the antigenicity of whey protein hydrolysates obtained by Papain and proleather enzymes after pressurization up to $400 \mathrm{MPa}$, and an absence of immunochemical reactivity in the peptides obtained after the hydrolysis of $\beta$-lactoglobulin by chymotrypsin under HP has been reported by Bonomi et al. (3).

However, to our knowledge, there is no information in the literature about the effect of the combination of HP and enzymatic proteolysis of cow's milk by food-grade proteases on the immunochemical reactivity of the protein hydrolysates.

The purpose of this study was to assess the residual antigenicity of the hydrolysis products obtained in the proteolytic digestion of bovine whey by food-grade enzymes in combination with HP, applied prior to or during the hydrolysis, with the aim of producing hydrolysates suitable for hypoallergenic infant formulae. 


\section{MATERIALS AND METHODS}

Sample preparation. Bovine whey was obtained from pasteurized skimmed bovine milk purchased in a Spanish supermarket and was converted to whey by acidification at $\mathrm{pH} 4.6$ with 4 $\mathrm{N}$ lactic acid. Then, the milk was centrifuged at $8,000 \times g$ for 15 min to remove the residual casein curd. The supernatant obtained was the whey, which was freeze dried and then dissolved in distilled water at a concentration of $5 \%(\mathrm{wt} / \mathrm{vol})$. HP used the whey solution (WP) as a substrate of the enzymatic hydrolysis performed after or during its treatment. The untreated WP was also hydrolyzed.

The $\mathrm{pH}$ of the WP was adjusted with $1 \mathrm{~N}$ sodium hydroxide (PRS grade, 98 to $100 \%$; Panreac, Barcelona, Spain) prior to its hydrolysis. The $\mathrm{pH}$ of the solution was 6 for the hydrolysis with Corolase PN-L (EC 3.4.21.63; AB Enzymes, Darmstadt, Germany) and 7 for the hydrolysis with Alcalase (EC 3.4.21.62; Novozymes, Bagsvaerd, Denmark), Neutrase (EC 3.4.24.28; Novozymes), Corolase 7089 (EC 1.5.1.15; AB Enzymes), and Papain (EC 3.4.22.2; Fluka, Buchs, Switzerland).

HP treatment. HP treatments were performed in a discontinuous HP machine (ACB GEC, Alsthom, Nantes, France) with a hydrostatic pump and a steel vessel of 2.35-liter capacity (100 $\mathrm{mm}$ in diameter and $300 \mathrm{~mm}$ in height). The vessel was filled with water as a fluid of low compressibility. During the treatment, the temperature was held constant by an external circulating thermostatic bath. In each experiment, the target pressure was achieved within 1 to $2 \mathrm{~min}$, held for $15 \mathrm{~min}$, and then released to atmospheric pressure within 1 to $2 \mathrm{~min}$. The treatments were repeated three times on individual samples.

The WP and the hydrolysis reactions, $15 \mathrm{ml}$ in all cases, were subjected to three different pressure treatments $(100,200$, and 300 $\mathrm{MPa})$ for $15 \mathrm{~min}$ at different temperatures $\left(40,50\right.$, or $\left.70^{\circ} \mathrm{C}\right) \mathrm{de}-$ pending on the protease used in the enzymatic reaction.

Proteolytic procedure. Three sets of experiments of proteolysis were separately performed with the following five enzymes: Alcalase, Neutrase, Corolase 7089, Corolase PN-L 100, and Papain. Alcalase is an endopeptidase from Bacillus licheniformis that cleaves the peptide bonds of protein near serine, glycine, and aromatic amino acids into large peptides; Neutrase is a metalloendopeptidase from Bacillus amyloliquefaciens that preferentially cleaves bonds involving hydrophobic amino acids; Corolase 7089 is an endoproteinase from Bacillus subtilis; Corolase PN-L is an endoproteinase and exopeptidase from Aspergillus sojae; and $\mathrm{Pa}-$ pain is a proteinase from Carica papaya with a broad specificity for peptide bonds and a preference for cleavage of a residue bearing a large hydrophobic side chain at the $\mathrm{P} 2$ position.

In the first set of experiments, the hydrolysates (HA) were produced at atmospheric pressure $(0.1 \mathrm{MPa})$ with untreated WP. These samples were considered the control of the experiments. An amount of $15 \mathrm{ml}$ of WP (5\%, wt/vol) and a 1:20 (vol/wt) enzymeto-substrate ratio (E:S) were used for the liquid enzymes (Alcalase, Neutrase, Corolase 7089, and Corolase PN-L) in the hydrolysis reactions. For Papain, the E:S ratio was 1:20 (wt/wt). Hydrolysis was carried out at $40^{\circ} \mathrm{C}$ for the reaction with Corolase $\mathrm{PN}-\mathrm{L}$, at $50^{\circ} \mathrm{C}$ for the reactions with Alcalase, Neutrase, and Corolase 7089 , and at $70^{\circ} \mathrm{C}$ for the reaction with Papain.

In the second set of experiments, the WP was packed into polyethylene bags and pressurized for 15 min prior to the enzymatic digestion (P100 to P300). The temperatures of the treatment were 40 and $70^{\circ} \mathrm{C}$ for the WP destined to be used for the hydrolysis with Corolase PN-L and Papain, respectively, and $50^{\circ} \mathrm{C}$ for use with Alcalase, Neutrase, and Corolase 7089. After the release of pressure, the treated WP was hydrolyzed at atmospheric pressure $(0.1 \mathrm{MPa})$ for $15 \mathrm{~min}$, as described above.

In the third set of proteolytic experiments, the WP was digested (HP, 100 to 300) under HP by the five proteases separately with the substrate concentration and E:S ratio as described above. The protease was added to the WP, and each mixture was distributed into polyethylene bags separately and maintained at $0^{\circ} \mathrm{C}$ until its incubation under pressure.

Incubations without enzymes were performed in the three sets of experiments; the hydrolysis was carried out in triplicate, stopped by heating for $5 \mathrm{~min}$ at $90^{\circ} \mathrm{C}$, and stored at $-20^{\circ} \mathrm{C}$ until analysis.

Allergic children. Sera used in this study were from 2 of 29 atopic children who arrived in 2004 at the emergency unit of Macedonio Melloni Hospital with acute allergic symptoms after ingestion of cow's milk formula. The two subjects presented the following clinical characteristics. Subject 1 was a male, aged 3.56 years, whose skin prick test yielded the following values: $\alpha$-lactalbumin, $15 \mathrm{~mm}$; casein, $6 \mathrm{~mm}$; and $\beta$-lactoglobulin, $8 \mathrm{~mm}$ (positive responses, $\geq 3 \mathrm{~mm}$ ). His CAP test (Pharmacia \& Upjohn Diagnostics, Uppsala, Sweden) yielded the following values: $\alpha$ lactalbumin, $3.09 \mathrm{kU} / \mathrm{liter}$; casein, $1.82 \mathrm{kU} / \mathrm{liter}$; and $\beta$-lactoglobulin, $<0.35 \mathrm{kU} /$ liter (positive responses, $>0.35 \mathrm{kU} / \mathrm{liter}$ ). Subject 2 was a female, aged 0.9 year, whose skin prick test yielded the following values: $\alpha$-lactalbumin, $6 \mathrm{~mm}$; casein, $10 \mathrm{~mm}$; and $\beta$ lactoglobulin, $12 \mathrm{~mm}$. Her CAP test (Pharmacia \& Upjohn) yielded the following values: $\alpha$-lactalbumin, $10.6 \mathrm{kU} / \mathrm{liter}$; casein, 19.3 $\mathrm{kU} / \mathrm{liter}$; and $\beta$-lactoglobulin, $2.71 \mathrm{kU} / \mathrm{liter}$.

They were not given an oral challenge because of the high risk of anaphylaxis. Informed consent was obtained from the parents of all children included in the study. Some control sera (healthy subjects) were tested for their reactivity to cow's milk proteins.

SDS-PAGE. The electrophoretic analysis of bovine whey hydrolysates was performed by nonreducing sodium dodecyl sulfate-polyacrylamide gel electrophoresis (SDS-PAGE) with a gradient running gel of 12 to $22 \%$ polyacrylamide, prepared according to Restani et al. (26), omitting 2-mercaptoethanol from the denaturing buffer. The gradient running gel was made up of 9 to $19 \%$ acrylamide; 0.08 to $0.17 \%$ bisacrylamide; $0.36 \mathrm{M}$ Tris- $\mathrm{HCl}$ buffer, $\mathrm{pH} 8.8 ; 35 \%$ glycerol; $0.1 \%$ SDS; $0.02 \%$ ammonium persulfate; and $0.15 \% N, N, N^{\prime}, N^{\prime}$-tetramethylenediamine. The stacking gel was made up of $3.5 \%$ acrylamide; $0.09 \%$ bisacrylamide; $0.125 \mathrm{M}$ Tris- $\mathrm{HCl}$ buffer, $\mathrm{pH}$ 6.8; 0.1\% SDS; $0.02 \%$ ammonium persulfate; and $0.15 \% N, N, N^{\prime}, N^{\prime}$-tetramethylenediamine. The running buffer was made up of $25 \mathrm{mM}$ Tris, $0.19 \mathrm{M}$ glycine, and $0.1 \%$ SDS (wt/vol), $\mathrm{pH} 8.8$.

After the electrophoretic run $(90 \mathrm{~V}$ at room temperature, for approximately $6 \mathrm{~h}$ ), gels were dyed with Coomassie brilliant blue G-250 by the method of Neuhoff et al. (15). All materials and instruments were purchased from Bio-Rad (Richmond, Calif.).

The molecular weights of the polypeptidic fragments obtained after the hydrolysis were determined with a broad-range molecular weight standard marker solution purchased from BioRad. It contained the following: rabbit skeletal myosin muscle $(200 \mathrm{kDa})$; Escherichia coli $\beta$-galactosidase (116.25 kDa); rabbit muscle phosphorylase $b(97.4 \mathrm{kDa})$; bovine serum albumin $(66.2$ $\mathrm{kDa}$ ); chicken egg ovalbumin (45 kDa); bovine carbonic anhydrase $(31 \mathrm{kDa})$; soybean trypsin inhibitor (21.5); chicken egg lysozyme $(14.4 \mathrm{kDa})$; and bovine pancreas aprotinin $(6.5 \mathrm{kDa})$.

Immunoblotting. After SDS-PAGE, proteins were transferred to a polyvinylidene difluoride membrane (Millipore Corp., 
Bedford, Mass.) by Western blotting in a Trans-blot Electrophoretic Transfer Cell (Bio-Rad).

The membranes were blocked with $1 \%$ gelatin and washed three times with $0.25 \%$ gelatin solution (in $150 \mathrm{mM} \mathrm{NaCl}, 5 \mathrm{mM}$ EDTA, $50 \mathrm{mM}$ Tris, and $0.05 \%$ Triton X-100) to prevent nonspecific adsorption of the immunological reagents. The membrane was then immersed in $10 \mathrm{ml}$ of $0.25 \%$ gelatin solution containing $0.3 \mathrm{ml}$ of sera from children allergic to cow's milk proteins or 10 $\mu \mathrm{l}$ of murine anti- $\beta$-lactoglobulin monoclonal antibodies (produced by ourselves). Since residual trace amounts of casein frequently remain in whey preparations, immunoblottings were also performed by anti-cow's milk protein polyclonal antibodies (produced by us) that recognized both whey proteins and caseins.

Secondary antibodies labeled with alkaline phosphatase detected antigen-antibody complexes. Specifically, goat anti-human immunoglobulin E antibodies (Sigma-Aldrich, St. Louis, Mo.) were for human sera, goat anti-mouse immunoglobulin $G$ antibodies (Sigma-Aldrich) were for monoclonal antibodies, and monoclonal anti-rabbit immunoglobulin $G$ antibodies were for polyclonal antibodies.

The secondary antibodies (commercial stock) were diluted $1: 1,000(\mathrm{vol} / \mathrm{vol})$ in $0.25 \%$ gelatin solution. After incubation for $4 \mathrm{~h}$ at room temperature with agitation, the membranes were washed twice with $0.25 \%$ gelatin solution ( 2 min each) and once with Tris Buffer Solution $(20 \mathrm{mM}$ Tris and $0.5 \mathrm{NaCl})$ for $2 \mathrm{~min}$.

Finally, after incubation in 5-bromo-4-chloro-3-indolylphosphate toluidinium-nitroblue tetrazolium (Merck, Darmstadt, Germany) solution, an intense black-purple precipitate developed at the site of enzyme binding. The developing solution contained 15\% 5-bromo-4-chloro-3-indolylphosphate toluidinium and 30\% nitroblue tetrazolium in alkaline phosphatase buffer (100 mM Tris, $100 \mathrm{mM} \mathrm{NaCl}$, and $5 \mathrm{mM} \mathrm{MgCl}$, $\mathrm{pH}$ 9.5).

Image analysis. Image analysis of membranes was performed by a gel scanner (Sharp JX-330, Pharmacia Biotech, Uppsala, Sweden) and Image Master 1D Software.

\section{RESULTS AND DISCUSSION}

Immunoblotting with monoclonal and polyclonal antibodies and the sera of allergic patients was used to check the effect of HP on immunochemical properties of dairy whey (WP) hydrolysates obtained by five food-grade enzymes. The electrophoretic separation of the hydrolysis products showed that the application of HP prior to or during enzymatic digestion enhanced the extent of proteolysis compared with the control and also affected the aggregation-polymerization patterns (data not shown). Papain produced the highest levels of hydrolysis at all tested conditions when compared with the other enzymes. No protein or aggregate bands were observed in Papain digestion of untreated and pressurized WP proteins, before or during their enzymatic treatments. All hydrolysates showed bands with an apparent molecular mass that was $<14.4 \mathrm{kDa}$.

Our findings on the increase of the extent of hydrolysis when the digestion was performed in combination with HP treatment are in consensus with the results reported by several authors for dairy and soy proteins $(13,19,29,31)$. The structure of the proteins at the secondary, tertiary, and quaternary levels could be affected by pressure (12) leading to protein denaturation $(1,2,11,28)$, a phenomenon that may favor their attack by proteolytic enzymes, enhancing the proteolysis.
Evaluation of the presence of $\beta$-lactoglobulin in bovine whey hydrolysates. Since $\beta$-lactoglobulin is the main allergen among cow's milk whey proteins (17), the presence of residues of this protein in different hydrolysates was evaluated with monoclonal anti- $\beta$-lactoglobulin antibodies. The results obtained with Alcalase are shown in Figure 1a. Antibodies recognized protein bands at the $R_{f}$ of $\beta$-lactoglobulin in the unhydrolyzed bovine whey (HU). Also, a positive reaction was observed for hydrolysates obtained at atmospheric pressure (HA) and when HP treatment at 100 and $200 \mathrm{MPa}$ was applied before the proteolysis (P100 and P200). However, a complete lack of immunoreactivity was found in products obtained under HP (HP100, HP200, and HP300) and with prepressurization at $300 \mathrm{MPa}(\mathrm{P} 300)$.

The same pattern was detected for all peptides resulting from the proteolytic attack by Neutrase (Fig. 1b), where the antigenic responses specific for $\beta$-lactoglobulin were associated with the control hydrolysates (HA) and those obtained after the HP treatment (P100, P200, and P300). A lower antigenic response was found for samples hydrolyzed under HP (HP100, HP200, and HP300), and positive reactions were mainly associated with polymeric forms of $\beta$ lactoglobulin.

These results suggest that the application of HP during the enzymatic digestion by Alcalase and Neutrase was able to improve the hydrolysis of the antigenic determinants of $\beta$-lactoglobulin. On the other hand, positive responses associated with $\beta$-lactoglobulin were observed in all patterns from Corolase 7089 proteolysis (Fig. 1c), with the exception of the hydrolysis product obtained at $300 \mathrm{MPa}$ (HP300), which showed no positive response. Samples hydrolyzed at 100 and 200 MPa (HP100 and HP200) showed lower immunochemical reactivity when compared with those pretreated by HP (P100 and P200), and these samples also showed a positive response to polymeric forms of $\beta$ lactoglobulin. These findings confirmed once more that the highest reduction of the antigenicity occurred when pressure was applied during the enzymatic hydrolysis.

A positive reaction associated with $\beta$-lactoglobulin was found for hydrolysis products obtained by Corolase PN-L (Fig. 1d), although the antigenic response was lower in hydrolysates obtained under and after pressurization at 300 MPa (lanes HP300 and P300, respectively).

Negative responses were obtained in all Papain hydrolysates (Fig. 1e), confirming the extensive hydrolysis of whey proteins by this enzyme observed in the electrophoretic analyses.

Our findings suggest that HP combined with enzymatic hydrolysis reduced the antigenic response of the hydrolysates when compared with the results of hydrolysis at atmospheric pressure. Several authors have reported on the denaturation of proteins under HP at specific cleavage sites that favor the accessibility of the proteases to the proteins $(3,4,9,13,19,29)$, which could lead to the elimination of their antigenic determinants. Our results show that the pressure treatment applied during the enzymatic digestion was more effective on the reduction of the immunoreactivity than when it was applied before the proteolysis. This phenomenon could be related to the structural unfolding and 

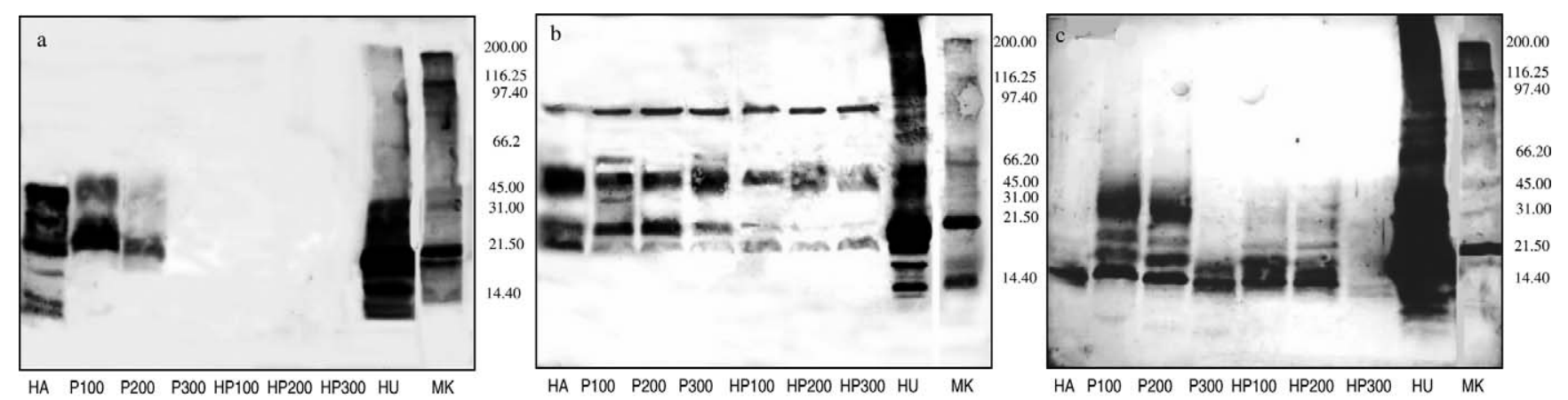

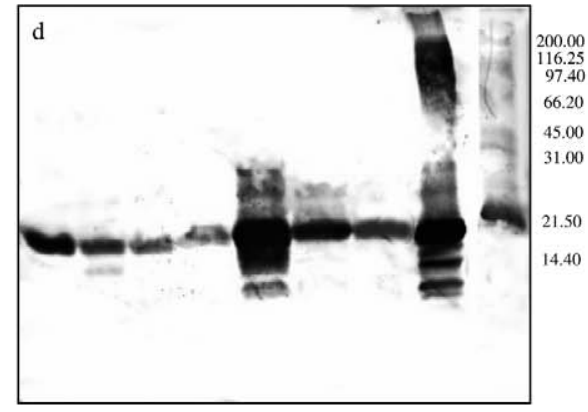

HA P100 P200 P300 HP100 HP200 HP300 HU MK

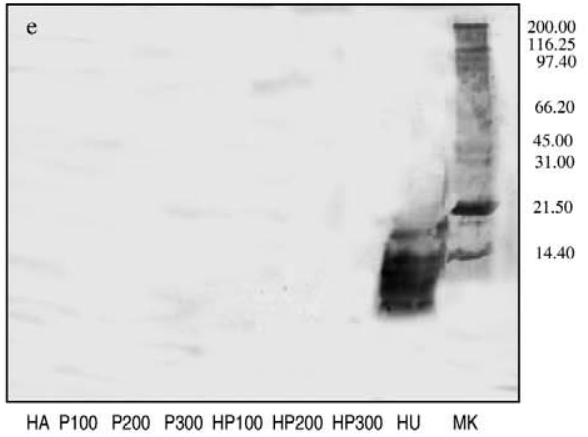

HA P100 P200 P300 HP100 HP200 HP300 HU MK

FIGURE 1. Immunoblotting of polypeptides obtained by hydrolysis of bovine whey proteins with Alcalase (a), Neutrase (b), Corolase 7089 (c), Corolase PN-L (d), and Papain (e) incubated with monoclonal anti- $\beta$-lactoglobulin antibodies. MK, molecular weight standard solution; HU, unhydrolyzed bovine whey; HA, hydrolysis at atmospheric pressure (0.1 MPa); P100, hydrolysis after pressurization at $100 \mathrm{MPa}$; P200, hydrolysis after pressurization at $200 \mathrm{MPa}$; P300, hydrolysis after pressurization at 300 MPa; HP100, hydrolysis at $100 \mathrm{MPa}$; HP200, hydrolysis at $200 \mathrm{MPa}$; HP300, hydrolysis at $300 \mathrm{MPa}$.

denaturation of WP proteins induced by $\operatorname{HP}(8,27)$ in the moment that the enzymes were present, which could favor the exposure of conformational antigenic epitopes to proteases.

Evaluation of the presence of bovine caseins in bovine whey hydrolysates. To evaluate the possible presence of bovine casein traces in bovine whey hydrolysates, polyclonal antibodies produced against all cow's milk proteins were used. The results obtained are shown in Figure 2.

In spite of their low specificity against $\beta$-lactoglobulin, these polyclonal antibodies confirmed the data shown in Figure 1 and, moreover, allowed us to conclude that the presence of a significant quantity of casein was excluded in the Alcalase, Corolase 7089, and Papain hydrolysates obtained at atmospheric pressure (control) and by HP applied prior to or during the enzymatic digestion (Fig. 2a, c, and d). By contrast, a positive reaction associated with casein was found for the hydrolysis products obtained by Neutrase and HP, although the antigenic response was lower in hydrolysates obtained at or after pressurization at 200 and $300 \mathrm{MPa}$ (Fig. 2b) and by Corolase PN-L when WP was subjected to pressurization before enzymatic digestion (Fig. 2d, lanes P100, P200, and P300). Negative responses were, however, observed in Corolase PN-L hydrolysates performed at 100, 200, and $300 \mathrm{MPa}$ (Fig. 2d, lanes HP100, HP200, and HP300).
Immunoblotting with sera of children allergic to cow's milk. To verify the immunoreactivity of the hydrolysates assayed in this research, immunoblottings with sera from two children allergic to whey proteins were performed.

Since the data obtained for the incubation of the membranes with the two sera were similar, only the results from one child are shown in Figure 3. The results obtained with human sera are very similar to those obtained with the polyclonal antibodies (Fig. 2) developed against all cow's milk proteins and confirm previous reports on the reduction of the protein antigenicity by combining HP treatment and enzymatic proteolysis $(3,14,17,20)$. Besides, these findings are in agreement with the results obtained by our group on the decrease of immunoreactivity of soybean whey proteins (19) and bovine whey proteins hydrolyzed by trypsin and pepsin in combination with pressure treatment (18).

The results of the present study suggest that the combination of high hydrostatic pressure and enzymatic proteolysis with selected food-grade proteases can decrease or remove the immunochemical reactivity of whey protein hydrolysates and that these methods can be applied in the production of hypoallergenic infant formulae. Further studies are now in progress to optimize the pressure-enzymatic treatments in order to remove completely the antigenicity of whey protein hydrolysates. Moreover, other in vitro and in vivo tests will be performed to confirm the results ob- 


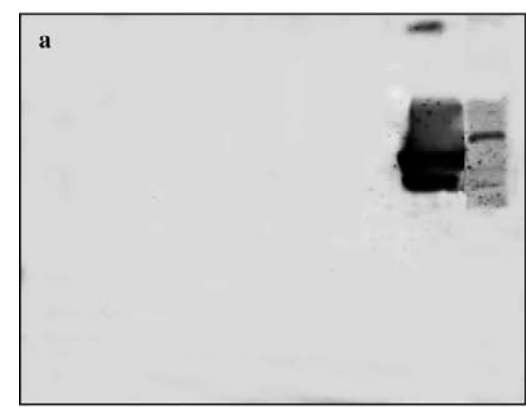

HA P100 P200 P300 HP100 HP200 HP300 HU MK

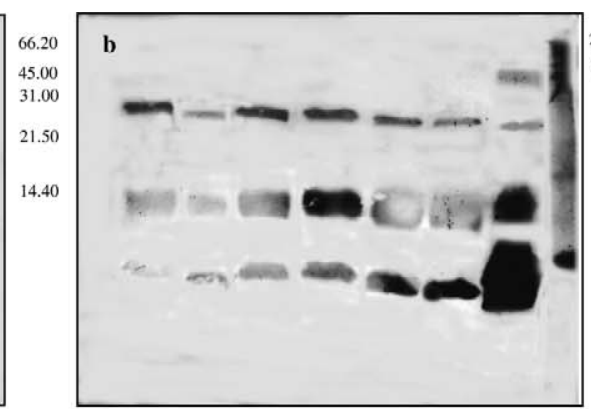

HA P100 P200 P300 HP100 HP200 HP300 HU MK

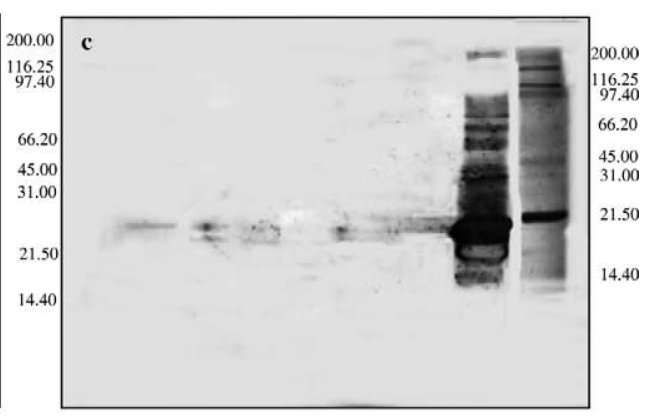

HA P100 P200 P300 HP100 HP200 HP300 HU MK

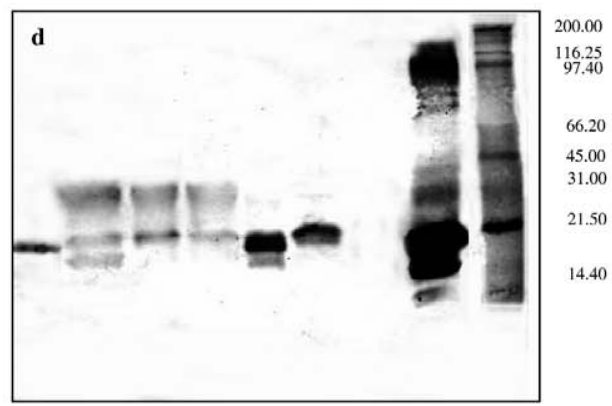

HA P100 P200 P300 HP100 HP200 HP300 HU MK

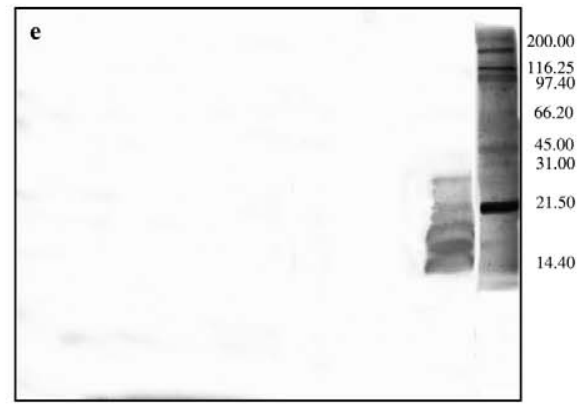

HA P100 P200 P300 HP100 HP200 HP300 HU MK

FIGURE 2. Immunoblotting of polypeptides obtained by hydrolysis of bovine whey proteins with Alcalase (a), Neutrase (b), Corolase 7089 (c), Corolase PN-L (d), and Papain (e) incubated with polyclonal anti-cow's milk protein antibodies. MK, molecular weight standard solution; HU, unhydrolyzed bovine whey; HA, hydrolysis at atmospheric pressure (0.1 MPa); P100, hydrolysis after pressurization at $100 \mathrm{MPa}$; P200, hydrolysis after pressurization at $200 \mathrm{MPa}$; P300, hydrolysis after pressurization at $300 \mathrm{MPa}$; HP100, hydrolysis at $100 \mathrm{MPa}$; HP200, hydrolysis at $200 \mathrm{MPa}$; HP300, hydrolysis at $300 \mathrm{MPa}$.

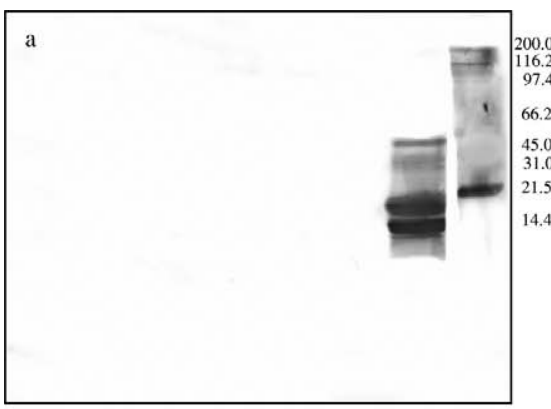

HA P100 P200 P300 HP100 HP200 HP300 HU MK

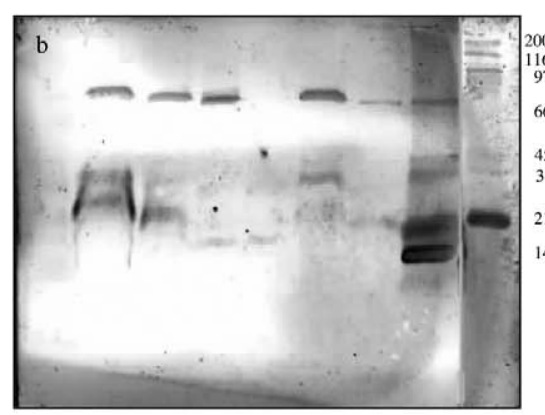

HA P100 P200 P300 HP100 HP200 HP300 HU MK

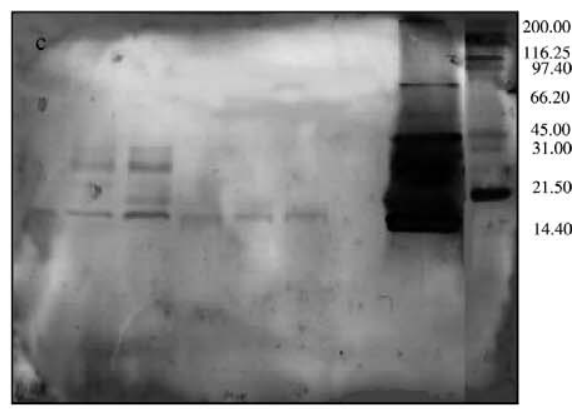

HA P100 P200 P300 HP100 HP200 HP300 HU MK

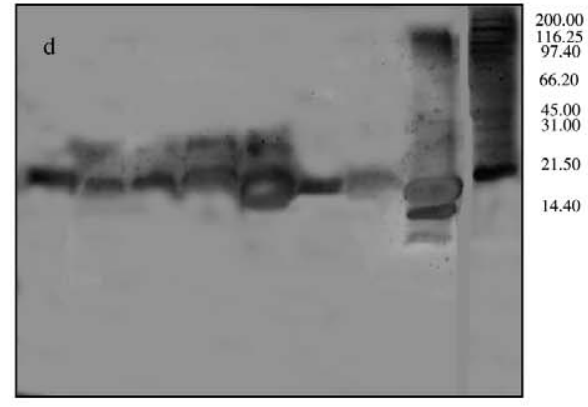

HA P100 P200 P300 HP100 HP200 HP300 HU MK

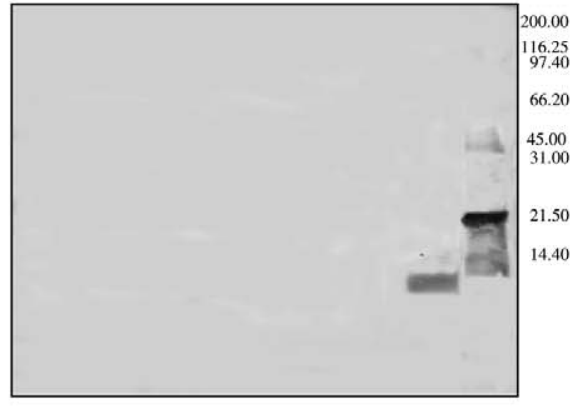

HA P100 P200 P300 HP100 HP200 HP300 HU MK

FIGURE 3. Immunoblotting of polypeptides obtained by hydrolysis with Alcalase (a), Neutrase (b), Corolase 7089 (c), Corolase PN-L (d), and Papain (e) incubated with the serum of a child allergic to cow's milk. MK, molecular weight standard solution; HU, unhydrolyzed bovine whey; HA, hydrolysis at atmospheric pressure (0.1 MPa); P100, hydrolysis after pressurization at $100 \mathrm{MPa}$; P200, hydrolysis after pressurization at $200 \mathrm{MPa}$; P300, hydrolysis after pressurization at $300 \mathrm{MPa}$; HP100, hydrolysis at $100 \mathrm{MPa}$; HP200, hydrolysis at $200 \mathrm{MPa}$; HP300, hydrolysis at $300 \mathrm{MPa}$. 
tained, and the clinical tolerance of these new formulae must be verified.

\section{ACKNOWLEDGMENT}

The "Comisión Interministerial De Ciencia y Tecnología" through project AGL2000-1497 supported this work.

\section{REFERENCES}

1. Balny, C., and P. Mason. 1993. Effects of high pressure on proteins. Food Rev. Int. 9:611-628.

2. Balny, C., P. Mason, and K. Heremans (ed.). 2002. Frontiers in high pressure biochemistry and biophysics. Elsevier, Amsterdam.

3. Bonomi, F., A. Fiocchi, H. Frokjaer, A. Gaiaschi, S. Iametti, C. Poiesi, P. Rasmussen, P. Restani, and P. Rovere. 2003. Reduction of immunoreactivity of bovine $\beta$-lactoglobulin upon combined physical and proteolytic treatment. J. Dairy Res. 70:51-59.

4. Bonomi, F., S. Iametti, C. Castagna, G. F. Dall'Aglio, and P. Rovere. 1999. Proteolysis of bovine $\beta$-lactoglobulin and chicken egg ovalbumin during treatment at high pressure, p. 289-292. In H. Ludviwg (ed.), Advances in high pressure bioscience and biotechnology. Springer, Heidelberg.

5. Calvo, M. M., and R. Gomez. 2002. Peptidic profile, molecular mass distribution and immunological properties of commercial hypoallergenic infant formulas. Milchwissenschaft 57:187-190.

6. Dufour, E., G. Hervé, and T. Haertle. 1992. Limited proteolysis of bovine $\beta$-lactoglobulin with thermolysin under high pressure, $\mathrm{p}$. 147-150. In C. Balny, R. Hayashi, K. Heremans, and P. Masson (ed.), High pressure and biotechnology. Institut National de la Santé et de la Recherche Médicale, Paris.

7. Dufour, E., G. Hervé, and T. Haertle. 1995. Hydrolysis of $\beta$-lactoglobulin by thermolysin and pepsin under high hydrostatic pressure. Biopolymers 35:475-483.

8. Dumay, E. M., M. T. Kalichevsky, and J. C. Cheftel. 1994. Highpressure unfolding and aggregation of $\beta$-lactoglobulin and the baroprotective effects of sucrose. J. Agric. Food Chem. 42:1861-1868.

9. Hayashi, R., Y. Kawamura, and S. Kunugi. 1987. Introduction of high pressure to food processing: preferential proteolysis of $\beta$-lactoglobulin in milk whey. J. Food Sci. 52:1107-1108.

10. Høst, A., S. Husby, and O. Østerbakkem. 1988. A prospective study of cow's milk allergy in exclusively breast-fed infants: incidence, pathogenic role of early inadvertent exposure to cow's milk formula, and characterization of bovine milk protein in human milk. Acta Paediatr. Scand. 77:663-670.

11. Iameti, S., P. Transidico, F. Bonomi, G. Vecchio, P. Pittia, P. Rovere, and G. Dall'Aglio. 1997. Molecular modifications of $\beta$-lactoglobulin upon exposure to high pressures. J. Agric. Food Chem. 45:23-29.

12. Lullien-Pellerin, V., and C. Balny. 2002. High-pressure as a tool to study some proteins' properties: conformational modification, activity and oligomeric dissociation. Innov. Food Sci. Emerg. Technol. 3: 209-221.

13. Maynard, F., A. Weingand, J. Hau, and R. Jost. 1998. Effects of high pressure treatment on the tryptic hydrolysis of bovine $\beta$-lactoglobulin AB. Int. Dairy J. 8:125-133.

14. Nakamura, T., H. Sado, and Y. Syukunobe. 1993. Production of low antigenic whey protein hydrolysates by enzymatic hydrolysis and denaturation with high pressure. Milchwissenschaft 48:141-144.

15. Neuhoff, V., N. Arold, D. Taube, and W. Ehrhardt. 1988. Improved staining of proteins in polyacrylamide gels including isoelectric focusing gels with clear background at nanogram sensitivity using Coomassie Brilliant Blue G-250 and R-250. Electrophoresis 9:550552.

16. Neville, M. C., J. C. Allen, P. C. Archer, C. E. Casey, J. Seacat, R. P. Keller, V. Lutes, J. Rasbach, and M. Neifert. 1991. Studies in human lactation milk volume and nutrient composition during weaning and lactogenesis. Am. J. Clin. Nutr. 54:81-92.

17. Okamoto, M., R. Hayashi, A. Enomoto, S. Kaminogawa, and K. Yamauchi. 1991. High-pressure proteolytic digestion of food proteins: selective elimination of $\beta$-lactoglobulin in bovine milk whey concentrate. Agric. Biol. Chem. 55:1253-1257.

18. Peñas, E., G. Préstamo, M. L. Baeza, M. I. Martínez-Molero, and R. Gómez. 2005. Effects of combined high pressure and enzymatic treatments on the hydrolysis and immunoreactivity of dairy whey proteins. Int. Dairy J., in press.

19. Peñas, E., G. Préstamo, and R. Gómez. 2004. High pressure and the enzymatic hydrolysis of soybean whey proteins. Food Chem. 85: 641-648.

20. Peñas, E., P. Restani, C. Ballabio, G. Préstamo, A. Fiocchi, and R. Gómez. 2005. Assessment of the residual immunoreactivity of soybean whey hydrolysates obtained by combined enzymatic proteolysis and high pressure. Eur. Food Res. Technol., in press.

21. Plebani, A., A. Albertini, S. Scotta, and A. G. Ugazio. 1990. Antibodies to hydrolysates of cow's milk proteins in children with cow's milk allergy. Ann. Allergy Asthma Immunol. 64:279-280.

22. Préstamo, G., and G. Arroyo. 2000. Preparación de macedonias con frutos tratados por alta presión. Alimentaria 318:25-30.

23. Préstamo, G., P. D. Sanz, and G. Arroyo. 2000. Fruit preservation under high hydrostatic pressure. High Pressure Res. 19:145-152.

24. Ragno, V., P. G. Giampietro, L. Bruno, and L. Businco. 1993. Allergenicity of milk protein hydrolysate formulae in children with cow's milk allergy. Eur. J. Pediatr. 152:760-762.

25. Restani, P., A. Plebani, T. Velonà, G. Cavagni, A. G. Ugazio, C. Poiesi, A. Muraro, and C. L. Galli. 1996. Use of immunoblotting and monoclonal antibodies to evaluate the residual antigenic activity of milk protein hydrolysed formulae. Clin. Exp. Allergy 26:11821187.

26. Restani, P., T. Velona, A. Plebani, A. G. Ugazio, C. Poiesi, A. Murazo, and C. L. Galli. 1995. Evaluation by SDS-PAGE and immunoblotting of residual antigenicity in hydrolysed protein formula. Clin. Exp. Allergy 25:651-658.

27. Silva, J. L., D. Fogel, and C. A. Royer. 2001. Pressure provides new insights into protein folding, dynamics and structure. Trends Biochem. Sci. 26:612-618.

28. Silva, S., and G. Weber. 1993. Pressure stability of proteins. Annu. Rev. Phys. Chem. 44:89-113.

29. Stapelfeldt, H., P. G. Petersen, K. R. Kristiansen, K. B. Qvist, and L. H. Skibsted. 1996. Effect of high hydrostatic pressure on the enzymatic hydrolysis of $\beta$-lactoglobulin B by trypsin, thermolysin and pepsin. J. Dairy Res. 63:111-118.

30. Van Beresteijn, E. C. H., J. G. M. Meijer, and D. G. Schmidt. 1995. Residual antigenicity of hypoallergenic infant formulas and the occurrence of milk-specific IgE antibodies in patients with clinical allergy. J. Allergy Clin. Immunol. 96:365-374.

31. Van Willige, R. W. G., and R. J. Fitzgerald. 1995. Tryptic and chymotryptic hydrolysis of $\beta$-lactoglobulin $\mathrm{A}, \mathrm{B}$, and $\mathrm{AB}$ at ambient and high pressure. Milchwissenschaft 50:183-186. 